\title{
A prática sinfônica e o mundo a seu redor
}

SAMUEL ARAUJO ${ }^{I}$

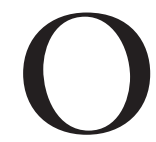
FOCO desta resenha-ensaio é estimular um debate sobre as relações entre práticas de música sinfônica e as demais práticas musicais presentes no mundo contemporâneo. O que denomino aqui práticas de música sinfônica abrange desde aquelas entendidas como prática comum, com repertório mais ou menos padronizado e apresentado sob a forma de concerto, até suas derivadas, que englobam desde música de câmara ou canto coral ao uso de orquestras sinfônicas em contextos distintos da prática comum, mas nos quais, ainda assim, são ou foram empregadas orquestras com alguma regularidade, e eventualmente também a grandes conjuntos instrumentais heterodoxos em que há introdução de, por exemplo, instrumentos de uso tradicional em determinadas culturas musicais, ou mesmo casos em que há a substituição integral dos instrumentos da tradição sinfônica por outros instrumentos não usuais daquela tradição.

Um traço comum a destacar em todos esses casos é a manutenção de um ideal simultaneamente sonoro e social ainda ligado à palavra sinfonia, originalmente associada à ideia de polifonia e, consequentemente, à ideia de uma coletividade constituída por relações entre múltiplas individualidades. Em determinados tempo e lugar ela será associada a grandes conjuntos instrumentais e a seu repertório. Outro termo-chave para nossa argumentação é a palavra concerto, que possui uma raiz etimológica bipartida entre, por um lado, combater ou competir, e, por outro, entrelaçar, atar ou argumentar. Este seria, portanto, um primeiro ponto a discutir: a orquestra como um dos modelos típicos de organização social do mundo moderno, com base na mediação racional de conflitos, dos mais atemporais aos inerentes à competitividade capitalista, lado a lado de instituições políticas de tipo republicano. Em outras palavras, os termos sinfonia e concerto remetem a um modelo de organização social em que há grande diversidade humana, e portanto conflitos a serem administrados e superados, com vistas ao melhor resultado coletivo possível, através da delegação de poderes a representantes (deputados, senadores, presidente na República, líderes de naipe, spalla e regente na orquestra).

Segue-se que as orquestras devem ser vistas também como parte do desenvolvimento da divisão social do trabalho que caracteriza as oficinas de manufatura na etapa mercantil do desenvolvimento do capitalismo e, mais tarde, as fábricas do mundo industrial. Dessa nova realidade histórica brota o conflito capital-trabalho que irá se acirrar mais e mais à medida que o capitalismo de base 
industrial se torna a força política hegemônica no plano global, produzindo, entre as orquestras sinfônicas, a conscientização crescente dos músicos sobre a disjunção de poder entre o "chão da fábrica" orquestral e seus "deputados", "gerentes" e "patrões", enquanto, no seio de regimes republicanos, orquestras sinfônicas passam a ser vistas como sinal de cultivo associado às elites intelectuais e econômicas, ainda que não restritas às mesmas.

Na França da primeira metade do século XIX, como relata a musicóloga norte-americana Jane Fulcher (1979), uma ideia surgida de iniciativa individual de prática coral dirigida originalmente a camponeses é adotada como ponto de partida para a primeira política pública republicana de alcance nacional relativa à música, a instituição dos chamados orfeões, dirigidos à classe trabalhadora. Os orfeões consistiam de prática de música principalmente vocal, mas também instrumental, a partir de repertórios compostos por músicos com formação acadêmica, com base em processos de composição de música de concerto "facilitados" para a execução por indivíduos com pouca ou nenhuma aspiração à profissionalização no campo da música, em geral trabalhadores aos quais alguns patrões concediam dispensa parcial de suas prolongadas e extenuantes tarefas diárias no chão de fábrica. Como demonstra Fulcher, é grande a ressonância da prática orfeônica nos conservatórios, imprensa musical e diária, e entre os meios intelectuais e políticos franceses da época, percebendo-se nessa um grande potencial de harmonização social em face dos constantes conflitos entre capital e trabalho, que irão se agravar ao longo do século. No entanto, tais conflitos logo irão se agravar a tal ponto que destruirá as ilusões de que uma prática musical possa ser modelo de organização social acima dos problemas de outra ordem que afligem determinadas sociedades. $\mathrm{O}$ exemplo das sociedades orfeônicas no século XIX coloca, portanto, em xeque as inúmeras iniciativas de hoje, pelo mundo afora, de investimento na prática sinfônica como ferramenta de combate às desigualdades socioeconômicas, questão a que voltarei mais adiante.

Em paralelo ao que ocorre no continente europeu, a orquestra passa a ser, em áreas do mundo sob o jugo colonial, simultaneamente uma expressão do poder e da opressão das metrópoles e uma metáfora de organização republicana de um Estado-nação por sobre divisões étnicas, linguísticas ou religiosas, ou seja, de construção de um todo político acima de diferenças, desigualdades, conflitos e exploração em seu interior. No entanto, desde o surgimento dos meios técnicos de reprodução e difusão em massa de música, a chamada música popular comercial se mostra capaz de produzir de modo mais eficaz tal simulacro de inclusão e coesão nacional, outrora exclusivo da prática sinfônica, ou mesmo produzir imagens não tão ilusórias de uma ordem igualitária, republicana, e até exemplos concretos de ascensão social pela música, embora, como na vida real, limitados a uns poucos casos isolados.

A realidade pós-industrial que se aprofunda a partir da segunda metade do século XX produz a crise do modelo fabril e do modelo orquestral-sinfônico 
(precarização do trabalho no "chão da fábrica", centralização de poder limitadas a um restrito núcleo decisório, com ênfase acentuada em aspectos gerenciais como marca, patrocínio, custo-benefício, propaganda). Orquestras passam a ser equacionadas como um problema contábil, exigindo um enfoque empresarial ajustado aos novos tempos, algumas são extintas, e algumas se redesenham em termos de repertório, público alvo, modo de apresentação e arregimentação de músicos, ou ajustam seu funcionamento aos modelos de negócio do mundo pós-industrial. ${ }^{1}$ Outras se reinventam como modelo de combate às desigualdades socioeconômicas, recrutamento de músicos entre a classe trabalhadora.

Nesse contexto, as relações das práticas sinfônicas com outras culturas musicais se produzem em meio a certa fascinação pelo modelo republicano de igualdade relativa possível e seu oposto, a rejeição, mais ou menos ativa, dirigida a ideais de centralização de poder e uniformização de repertório presentes em práticas sinfônicas. As iniciativas de aproximação entre o mundo sinfônico e aquele a seu redor são as mais diversas, podendo ir da forte incorporação de repertório e instrumentação de outras tradições musicais à formação orquestral sinfônica mais ortodoxa até a adoção, parcial ou total, de repertórios que circulam por outros espaços sociais, com inclusão ou não de instrumentos próprios a esses repertórios. Os seus exemplos mais conhecidos e com repercussão em âmbito internacional, notadamente os chamados nacionalismos musicais ou as estéticas socialistas, são momentos em que estética, política e transformação social são motivações organicamente interligadas, e com isso chego a algumas perguntas pertinentes a esse debate:

- as relações da prática sinfônica nos tempos de hoje com as demais práticas musicais à sua volta são moldadas a partir de um real interesse estético e político de transformação social ou seriam apenas uma estratégia de autossobrevivência em meio a uma realidade desfavorável em termos sociais e econômicos, pouco se importando com a redução ou superação dos graves problemas sociais de nosso tempo?

- as atuais iniciativas de expansão dos objetivos e diversificação dos públicos, contextos e espaços para a prática sinfônica refletem uma real subversão dos princípios de exclusividade, competitividade e profissionalismo dessa prática ou permanecerão vistos tão somente como atividade menor, e no máximo como uma estratégia para continuar alimentando o mercado da sala de concerto e endossando atividades de formação com ênfase naqueles mesmo princípios em conservatórios e escolas universitárias de música?

- as celebradas transformações no campo da formação de músicos de orquestra, notadamente o recrutamento de jovens das periferias para a prática sinfônica, têm sido de fato bem-sucedidas em revitalizar as práticas sinfônicas ou se limitam a lidar produtivamente com os efeitos da precarização do trabalho na sociedade pós-industrial e reproduzir os ideais de domesticação social da classe trabalhadora em moldes análogos aos da prática do orfeão comentada anterior- 
mente, muitas vezes com o efeito colateral de desqualificar as práticas musicais dessa mesma classe?

Abordando essas e outras questões pertinentes, o provocativo e bem documentado livro do musicólogo britânico Geoffrey Baker aborda o programa público venezuelano conhecido como El Sistema, designação curta e mais popular da Federação Nacional de Orquestras Juvenis e Infantis da Venezuela (Fenojiv). Com repercussão internacional como modelo de ensino e promoção da música sinfônica voltados à infância e à juventude, foi fundado em 1975 pelo economista, político, músico e gestor público José Antonio Abreu e um grupo de músicos do campo sinfônico em Caracas, se estabelecendo pouco a pouco em diferentes regiões do país. O fato de ser o primeiro estudo crítico de fôlego sobre programa público de tão longa duração (exatos quarenta anos!) e tamanho renome e influência já despertaria em si motivo de curiosidade entre acadêmicos de diferentes áreas, artistas, educadores e gestores culturais. Mas o livro não se limita a preencher essa lacuna e vai muito além, colocando em xeque ideias influentes e lugares-comuns acerca de temas como arte e política, ideologias da arte como valor humano absoluto, o papel pedagógico das artes e o emprego da arte como ferramenta de enfrentamento das desigualdades e injustiças sociais. Com produção sistemática e diversificada sobre a música na América Latina, Baker se propõe a preencher essa paradoxal lacuna, tão óbvia quanto intrigante. Tamanho enigma se adensa ainda mais pelo fato de a projeção de El Sistema ter canalizado crescente apoio interno e externo desde 1975, atravessando governos com perfis políticos marcadamente opostos, atraindo substanciais investimentos públicos e privados, e extraindo elogios retumbantes de figuras exponenciais do mundo da música de concerto, como os regentes Simon Rattle e Claudio Abbado, ou o cantor e também regente Plácido Domingo. Rattle, em particular, celebrou El Sistema como a principal novidade e esperança de revitalização da música de concerto no século XX, em movimento contrário à notável retração dessa nos circuitos internacionais.

Com propósito de interrogar criteriosamente os fatos que propiciaram tão favorável e abrangente repercussão, Baker muniu-se não somente de farta documentação primária, como informação em sítios eletrônicos e documentários audiovisuais, fatores de boa parte da repercussão positiva do programa, mas passou cerca de um ano em trabalho de campo na Venezuela, visitando núcleos de ensino e performance, registrando em primeira mão e analisando com o devido cuidado suas práticas diárias e eventos públicos, e entrevistando indivíduos envolvidos em alguma instância com o tema em estudo, como alunos, familiares, professores, músicos, ex-participantes e ex-gestores. A cada capítulo, esse trabalho empírico é posto em diálogo com literatura crítica interdisciplinar e multifocal de impressionante abrangência, incluindo a escassa produção acadêmica existente sobre El Sistema. Educação musical, musicologia, etnomusicologia, história, política, economia, pedagogia, psicologia, gestão pública e música 
sinfônica são quiçá os mais proeminentes campos e temas visitados no livro, trazendo perspectivas que problematizam agudamente muitos truísmos acerca da música e de seus supostos efeitos humanos e sociais positivos, criados a partir de ideais centro-europeus e difundidos pelo mundo afora através do processo civilizatório colonial. Sobre essa sólida base e de modo detalhado, Baker examina criticamente ponto a ponto das narrativas oficiais, jornalísticas e as poucas com inclinação mais acadêmica produzidas em torno do sistema de orquestras juvenis e infantis venezuelano, e em geral tomadas como fonte de ratificação de sua repercussão artística e social.

O livro é organizado em quatro partes, cada uma delas dividida em número variável de capítulos. Abrem a primeira parte ("A instituição e seus líderes") dois capítulos sobre as trajetórias respectivas de Abreu (I) e das duas principais vitrines internacionais de El Sistema, o renomado regente Gustavo Dudamel e a Orquestra Jovem Simón Bolivar (II). Os dois capítulos finais tratam dos aspectos organizacionais e da dinâmica de El Sistema (III), bem como de seus aspectos demográficos e históricos (IV).

Criado com objetivos exclusivos de difusão e revitalização da música sinfônica no país, em contexto de governos desenvolvimentistas e modernizantes, El Sistema apresentava como eixo inicial práticas de ensino vistas como inovadoras, contrastantes às dos conservatórios convencionais do país, como ensino coletivo, e não individualizado, de instrumentos centrado exclusivamente no repertório sinfônico, o emprego de ex-estudantes não diplomados, embora experientes, como mestres de novos aprendizes e a remuneração dos aprendizes com bolsas de estudo. Outro diferencial já nessa primeira etapa foi o apoio governamental assegurado pela ligação estreita de Abreu com as forças conservadoras hegemônicas na política venezuelana dos anos 1970, elo que o levaria a ministro da Cultura e presidente do Conselho Nacional de Cultura durante o segundo governo de Carlos Andrés Pérez (1989-1993). Sendo o financiamento, como aponta Baker com base na literatura, fator-chave para o sucesso ou não no mundo extremamente competitivo das orquestras sinfônicas, esse apoio estatal proporcionou fundos suficientes para tornar realidade um programa de formação de tais orquestras, ramificado em núcleos espalhados em diferentes regiões do país, e fazer repercutir internacionalmente o brilho de alguns de seus expoentes como Dudamel e a Simón Bolivar. Contudo, como detalhadamente exposto no livro a partir de entrevistas e observação participante, as práticas centralizadoras e a escala de valores vigentes em El Sistema não se diferenciavam, nem se diferenciam atualmente, do habitual recorte excludente, hierárquico, competitivo e autoritário vigente, com raríssimas exceções, no campo sinfônico profissional em qualquer parte do mundo. Seu repertório tampouco era ou passou posteriormente a ser diferente daquele concentrado no cânone centro-europeu criado entre meados do século XVIII e início do século XX, igualmente usual em orquestras sinfônicas profissionais em todo o mundo. 
A partir da segunda metade dos anos 1980, passaram a ecoar no país crescentes clamores de movimentos sociais por mudanças políticas, culminando na posse de Hugo Chávez em 1999. Esta rompeu com a centralização do poder em torno dos três partidos, até então dominantes na política venezuelana, e simultaneamente com os modos de governo concentradores e clientelistas anteriores, através da adoção de processos decisórios participativos. Segundo relatam a Baker alguns integrantes de El Sistema à época, os documentos do programa e os pronunciamentos públicos de seu principal artífice, Abreu, captaram os novos ventos e a eles se ajustaram paulatinamente, mesmo antes da eleição de Chávez, desenvolvendo uma nova retórica de transformação humana e social através da música sinfônica, sem porém abandonar, em essência, valores, práticas e repertório anteriormente tomados como eixo. Essa mudança retórica, como apontam vozes críticas na Venezuela mapeadas por Baker, produz um desafiador paradoxo: o apoio do líder de um governo popular e participativo a um programa público que permaneceu, na prática, na contramão tanto da literatura crítica em música, educação e sociedade quanto do próprio processo político participativo na Venezuela, no qual tal governo encontrava (e até hoje encontra) sua legitimidade.

O capítulo de abertura (V) da segunda parte do livro (Educação musical) reflete sobre a literatura internacional acerca das orquestras sinfônicas em sentido amplo, das profissionais às infantojuvenis, interrogando as possíveis implicações artísticas, psicológicas, pedagógicas e político-sociais da prática sinfônica no mundo contemporâneo. Essa literatura se mostra em geral não convencida, se não absolutamente cética, diante da capacidade de a referida prática ser capaz de propiciar experiência humana positiva entre seus praticantes, sujeitos a processos, em geral, autoritários, manipuladores e psicossocialmente danosos. O capítulo final (VI) concentra o foco sobre as práticas de ensino e aprendizagem de El Sistema, com o autor estabelecendo um contraponto profícuo entre, por um lado, o que se diz e o que se escreve a respeito, e, por outro, o que se faz de fato. O dia a dia nos núcleos de El Sistema, observados por Baker em diferentes partes do país e também da capital, não diferiu das práticas comuns à prática orquestral convencional de tentativa-erro-correção-nova tentativa, e, em alguns casos não só observados diretamente mas a ele reportados em anonimato, muitas vezes envolvendo práticas de exposição intimidatória. Particularmente constrangedora entre estas últimas, embora não desconhecida em práticas corriqueiras de ensino conservatorial, é a exigência de que determinado instrumentista toque individualmente um trecho de execução coletiva perante seus colegas de naipe na expectativa de que atenda um padrão subjetivo e insondável exigido pelo regente, sem possibilidade de qualquer relação dialógica.

A terceira parte do livro (Educação social) coloca em discussão os potenciais da arte e da música em produzir cenários ideais de democracia e bem-estar social. Seu primeiro capítulo (VII) problematiza a ideia de ação social através da 
música, slogan hoje popularizado no debate público em diversos contextos internacionais, inclusive no Brasil. ${ }^{2}$ Mais uma vez por meio de contraponto entre pesquisa empírica e bibliográfica, Baker questiona a fundo o senso comum dominante acerca de termos como inclusão social e combate às desigualdades, em El Sistema matizados por inquietantes noções de disciplina e controle (VIII), assim como os valores propalados como centrais em documentos programáticos e declarações públicas de dirigentes do programa venezuelano, a saber, democracia, trabalho em equipe e meritocracia (IX). Em contradição com a anunciada ênfase sobre tais valores, Baker registra a intensa competitividade que permeia as relações entre participantes e núcleos de El Sistema nas diversas regiões do país, bem como a pouca transparência dos critérios frequentemente personalistas de promoção a melhores orquestras, concentradas em Caracas. Evidencia também haver queixas consideráveis de professores e músicos acerca da remuneração desigual entre os núcleos de elite concentrados em Caracas e aqueles, majoritários, à base do programa, expondo ainda mais a debilidade da formulação, defendida publicamente por Abreu, de ser El Sistema um modelo de vida social harmônica. Isso não impede, porém, que se encontrem entre seus participantes aqueles que avaliem como positiva sua experiência pessoal, mesmo entre aqueles que, não havendo chegado às melhores orquestras na Venezuela ou ao bem mais difícil estrelato internacional, tenham tido sua história escolar e rumo existencial de algum modo prejudicados pela dedicação desmesurada à prática orquestral. No entanto, pergunta-se Baker (X), seria essa autodeclarada satisfação de participantes, encontrada com certa regularidade nos assim chamados projetos sociais, um índice suficiente para avalizar as práticas e valores vigentes? Ou seria nesse caso, como lembrado pelo autor, mais um capítulo do drama colonial desde a Conquista, em que a mimese fetichizada, muitas vezes caricata, do colonizador é reclamada pelo colonizado como uma realização pessoal? Pelo que se lê no livro, a retórica social que serve hoje de eixo a El Sistema permanece longe de uma revolução cultural, mas é paradoxalmente corroborada, se não pelo governo venezuelano como um todo, pelo poder executivo, ecoando positivamente em setores da imprensa nacional e internacional, gravadoras e produtoras ligadas ao mundo sinfônico internacional e bancos intergovernamentais de fomento ao desenvolvimento.

A quarta parte do livro (Impacto) se volta àquele que parece ser o mais recorrente problema de programas de "ação social através da arte", mas também de políticas culturais de um modo geral, a avaliação de impacto desses. Sobre esse ponto não apenas ressurgem ideologias retrógadas defendendo existir um sentido humano e social intrinsecamente positivo na experiência artístico-cultural, mormente quando essa é avalizada pelas elites dirigentes, bem como persiste a dificuldade de se estabelecer parâmetros artísticos, sociais, políticos e econômicos que comprovem haver impacto sondável, positivo ou não, em tais políticas públicas e qual a sua medida. A esse respeito, a pesquisa que embasa o 
capítulo inicial (XI) revela haver um profundo desequilíbrio entre o montante substancial de recursos que financia El Sistema, entre os quais 500 milhões de dólares aportados por bancos de fomento ao desenvolvimento, e a falta de mecanismos de avaliação minimamente rigorosos de seus resultados. Tal fato não permite que se enxergue o programa como um todo, ofuscado por seus feitos inegáveis, devidamente reconhecidos pelo autor. Embora emanando de El Sistema, sugere Baker, tais realizações não podem ser tomadas como representativas do programa como um todo em razão dos escassos e, em geral, inconsistentes dados disponíveis, o que ao menos expõe a urgência de se repensar sobre bases mais sólidas os números do programa.

No capítulo seguinte (XII), o autor procura pensar o impacto da concepção monolítica de política pública para a música em questão, em torno do ideal sinfônico, o relacionando ao que estudiosos do clima vêm alertando como efeitos predatórios da monocultura e da exploração científica do meio ambiente. Neste último caso, alguns especialistas propõem que tais efeitos só passaram a ser tratados com a atenção e seriedade devida em estágio perigosamente próximo ao irreversível. É possível assim, alerta Baker, que, à falta de mais estudos, debate e monitoramento democrático, um eventual impacto predatório de El Sistema sobre o panorama musical venezuelano só se faça notar tardiamente, em que pesem as muitas críticas internas formuladas ao longo de décadas por músicos, acadêmicos (Pedroza, 2015), gestores públicos da cultura e ativistas, frequentemente referidos pelo autor. Segundo este último, há indícios de que tal esteja acontecendo, levando inclusive à abertura recente do programa à música popular, embora ainda não permitindo que se possa avaliar seu vigor de renovação dos pilares do programa.

O autor propõe ao final um balanço acerca do futuro da educação musical e da própria música na América Latina e em outros contextos, levando em consideração o inegável impacto de El Sistema para dar mais visibilidade internacional à área como um todo. Experiências baseadas em diferentes valores, práticas e/ ou repertórios afinal existem, na própria Venezuela, tanto no âmbito dos conservatórios quanto no de instituições alternativas anteriores ou contemporâneas à criação de El Sistema. Neste último caso, encontra-se o Instituto Interamericano de Etnomusicologia e Folclore (Inidef), criado por Isabel Aretz e Luiz Felipe Ramón y Rivera, instituição-chave na formação de uma geração seminal de etnomusicólogos sul-americanos, como Rafael José de Menezes Bastos, Rita Laura Segato, José Jorge de Carvalho e Terry Agerkop. Mais recentemente, uma rede de 27 escolas de música foi formada em Medelin, Colômbia, com base no ideal sinfônico do programa venezuelano, mas reorientou suas práticas a partir de 2005 rumo a músicas populares, práticas de instrumentos locais e foco agregado em composição. Outras, no Reino Unido, mantendo o foco em formações orquestrais e camerísticas, adotaram práticas contrastantes às habituais em tais formações, por exemplo, estimulando mais intervenção crítica dos 
músicos em geral e abrindo espaço a repertório contemporâneo e experimental, mitigando o peso da competitividade e do egocentrismo. Por fim, Baker faz remissão também a experiências relacionadas ao pensamento pedagógico radical latino-americano, tendo Paulo Freire como referência central e inspirando iniciativas como o programa público brasileiro Pontos de Cultura, implantado durante a gestão de Gilberto Gil no Ministério da Cultura, em que valores como autonomia, crítica e reflexão-ação foram instados a contribuir a um mundo mais participativo, justo e igualitário. Neste ponto, talvez faça falta ao leitor uma análise tão detalhada e crítica dessas experiências quanto a que Baker empreende em relação a El Sistema, pois nem sempre bons programas no papel também o são na prática, sua avaliação também requerendo abordagens etnográficas e perspectivas de médio e longo prazo. Embora devam reconhecer-se as limitações de tempo e espaço para que o próprio autor o faça no livro, ao menos no caso brasileiro, já há crescente bibliografia crítica sobre o programa referido, que talvez ajudasse a o situar, ainda que brevemente, em alguma perspectiva mais crítica.

Perguntas inquietantes e simultaneamente oportunas sobressaem da leitura. Seria sustentável usar-se, como propaga publicamente El Sistema e seu principal artífice, a orquestra sinfônica como metáfora de uma sociedade ideal? Seria verificável o papel das orquestras sinfônicas e da música de concerto em geral como alavancas de redução de desigualdades? Seria desejável, como objetivo educacional, enfatizar a reprodução de um repertório musical canônico centro-europeu criado entre meados do século XVIII e início do século XX? Seria justificável sacrificar-se, como apontado no livro, a trajetória dos participantes no sistema de ensino formal para lhes cobrar melhor desempenho como instrumentistas com ideais de excelência culturalmente limitados e historicamente ultrapassados? (Dias da Silva, 2011). O que dizer, em termos políticos, sociais e educacionais, da ênfase disciplinar e a centralização autoritária de decisões como método explícito para alcance de tais objetivos? Quais e onde estão documentados os critérios para a remuneração diferente entre professores e entre aprendizes de diferentes núcleos, bem como entre instrumentistas de diferentes orquestras em diferentes regiões do país? Haveria ganhos em se aceitar tacitamente os processos oclusos e violentos de humilhação individual, discriminação social, racial e de gênero, falta de transparência nas relações trabalhistas e reconhecimento de mérito artístico, jamais os expondo e, muito menos, sobre eles refletindo publicamente? (Selles, 2013). Por que se verifica ausência de avaliação externa pormenorizada, isto é, indo além da contabilização de êxitos difundidos com muita eficácia, e o que justificaria a indisponibilidade pública de indicadores de desempenho consistentes? Como explicar a inexistência de processos transparentes e participativos de autorreflexão e tomada de decisão, em contradição com os princípios da democracia participativa, marca política distintiva dos governos bolivarianos na Venezuela de Chávez a Maduro, gerando inclusive críticas públicas ao sistema nacional de orquestras formuladas por personagens 
de mais ou menos relevo ligados a esses governos? Por que não são ouvidas vozes de crítica e oposição a El Sistema em meio aos movimentos sociais e ações governamentais que defendem a democracia participativa na Venezuela?

As evidências apresentadas e analisadas por Baker com extremo equilíbrio e cuidado reflexivo, mas sem omissão ou complacência, oferecem um quadro a merecer muito mais atenção e escrutínio na Venezuela e no exterior. Demonstra-se que, em El Sistema, é forte a relação entre o efeito publicitário a partir de uma melíflua retórica salvacionista, aliado à performance de uma pequena fração de seus músicos e conjuntos de elite, e consequente uso oportunista por políticos de diferentes matizes (mais que por partidos ou movimentos sociais), bancos de fomento ao desenvolvimento, empresas e indivíduos de projeção. Predominaria assim, em suas ações, um uso instrumentalizado de políticas e financiamentos pretensamente benéficos para os setores mais pobres da infância e juventude venezuelanas, em favor de uma política conservadora de reprodução de prática sinfônica ultraconvencional, na contramão do pensamento e ação nos campos de performance e educação musicais, para não falar da literatura crítica sobre música em geral produzida internacionalmente nas últimas décadas.

Outras questões inquietantes se desdobram do exame do "modelo El Sistema" no livro. Seriam as características e efeitos apontados em tal modelo exclusivos de projetos ditos sociais que envolvem ensino e/ou prática de música sinfônica, ou podem ser encontrados em projetos semelhantes com outros conteúdos musicais como, digamos, música popular (definição impositiva de repertórios canônicos, ênfase em disciplina e reprodução, desprestígio de atividades reflexivas etc.)? Em que pesem os indicadores positivos em torno de uma porcentagem reduzida das ações e trajetórias dos participantes do sistema como um todo, quais os efeitos em médio e longo prazos que se podem esperar dos muitos problemas de um investimento social, político e financeiro tão grande, ainda mais se estiver correto o que sugere a literatura crítica especializada no que tange à crítica da orquestra sinfônica como modelo social, político e epistemológico (e, pode-se adicionar, financeiro) no mundo contemporâneo? Por fim, mais além de seu foco em El Sistema, orquestras sinfônicas ou política cultural na Venezuela, quais as implicações do debate em que se engaja Baker para discussões sobre o campo musical em outros contextos nacionais, como o do Brasil, regionais e globais?

A difusão e a repercussão dos assim chamados projetos sociais centrados no ensino e prática de artes, visando à redução de desigualdades socioeconômicas e/ou promoção de justiça social e apoiando-se em financiamento público e privado, são uma realidade palpável em termos internacionais desde pelo menos meados dos anos 1980. A já extensa literatura acadêmica sobre o assunto sugere que tal movimento reflete debates sobre pobreza, distribuição de renda e justiça social, formulações de bancos de fomento ao desenvolvimento, como o FMI e o BID, órgãos supranacionais, como a Unesco, ou órgãos estatais em diferentes 
países e ações tanto de ONG quanto do setor privado (Araujo; Cambria, 2013), este último, muitas vezes, em troca de polêmicos incentivos fiscais ou algum outro tipo de financiamento pelo setor público, não raro se valendo desses mecanismos para reinvestimentos que agreguem valor à marca da empresa promotora ou patrocinadora. Tal literatura problematiza particularmente o impacto dessas formulações para seus respectivos públicos-alvo (infância e juventude em "risco social", pobres, oprimidos, "excluídos") e sua aparição em concomitância e significativa relação com a crescente retração do investimento público global na produção artística per se, ou seja, investimento feito sem obrigatoriedade ou dependência de contrapartidas sociais. Tal quadro resultou na multiplicação exponencial e inegável visibilidade hoje constatável dos projetos sociais relacionados às artes, cuja relevância é justificada totalmente ou em grande medida por seu presumido papel de contribuição às causas sociais mais diversas. A pertinência desse uso instrumentalizado das artes no combate às desigualdades e ao que se passou a chamar de exclusão socioeconômica se tornou uma espécie de lugar-comum no debate público recente, raramente deparando com oposição audível além de determinados circuitos acadêmicos e produzindo rebatimentos sedutores em diversos âmbitos da educação e prática musicais. Deixa, porém, como nos incita a pensar o trabalho de Geoffrey Baker sobre El Sistema, muitas dúvidas no ar, abrangendo desde seus efeitos artísticos até seu estatuto enquanto valor humano, restando em aberto uma avaliação mais objetiva de seu efetivo impacto redutor de desigualdades e injustiças sociais além da retórica salvacionista que o reveste.

\section{Notas}

1 Este foi um dos principais focos de recente evento ocorrido na Cidade das Artes, Rio de Janeiro, a segunda edição da Conferência Internacional Multiorquestra (27 a 29 de abril de 2015), com apoio do programa Transform Orchestra Leadership do British Council.

2 Ver, por exemplo, Kleber (2014); Guazina (2011).

\section{Referências}

ARAUJO, S.; CAMBRIA, V. Sound praxis, poverty and social participation; perspectives from a collaborative study in Rio de Janeiro. Yearbook for Traditional Music, v.l, p.28-42, 2013.

BAKER, G. El Sistema; orchestrating Venezuelan youth. Oxford: Oxford University Press. 2014.

DIAS DA SILVA, A. A Maré no ritmo das ONGs: uma análise sobre o papel das oficinas musicais de organizações não-governamentais no bairro Maré, Rio de Janeiro. 2011. Dissertação (Mestrado em Música) - Universidade Federal do Rio de Janeiro. Rio de Janeiro, 2011.

FULCHER, J. The Orpheon Societies: “Music for the Workers" in Second-Empire 
France. International Review of the Aesthetics and Sociology of Music, v.10, n.1, p.47-56, jun. 1979.

GUAZINA, L. S. Práticas musicais em Organizações Não Governamentais: uma etnografia sobre a (re)invenção da vida. 2011. Tese (Doutorado em Música) - Universidade Federal do Estado do Rio de Janeiro. Rio de Janeiro, 2011.

KLEBER, M. O. A prática de educação musical em ONGs: dois estudo de caso no contexto urbano brasileiro. Curitiba: Appris, 2014.

PEDROZA, L. Of orchestras, mythos, and the idealization of symphonic practice: the Orquesta Sinfónica de Venezuela in the (collateral) history of El Sistema, Latin American Music Review, Austin, v.36, n.1, Summer 2015.

SELLES, J. M. Ensino da música sinfônica para jovens dos estratos subalternos: capital simbólico e controle social no capitalismo tardio. 2013. Dissertação (Mestrado em Música) - Universidade Federal do Rio de Janeiro. Rio de Janeiro, 2013.

Samuel Araújo é coordenador da pós-graduação em Etnomusicologia da Escola de Música da UFRJ. @- araujo.samuel@gmail.com

Recebido em 8.9.2015 e aceito 22.10.2015.

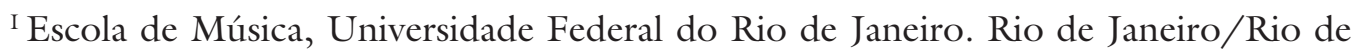
Janeiro, Brasil. 